\title{
SCHEDULING MAIZE IRRIGATION BASED ON CROP WATER STRESS INDEX (CWSI)
}

\author{
FATTAHI, K. ${ }^{1}-$ BABAZADEH, H. $.^{1}{ }^{2 *}-$ NAJAFI, P. ${ }^{1}-$ SEDGHI, H. ${ }^{1}$ \\ ${ }^{I}$ Department of Water Science and Engineering, Science and Research Branch, Ismaic Azad \\ University, Tehran, Iran \\ ${ }^{2}$ Department of Water Engineering, Khorasgan Branch, Islamic Azad University, Isfahan, Iran \\ *Corresponding author \\ e-mail: h_babazadeh@srbiau.ac.ir; phone: +98-912-699-0105
}

(Received $21^{\text {st }}$ Jun 2018; accepted $14^{\text {th }}$ Aug 2018)

\begin{abstract}
Qualitative and quantitative restrictions on water resources have given rise to large water stress on land and plants. The recognition of such stresses can be of help in crop management. Due to the large impact on yield, water stress plays an important role in planning proper irrigation, timing, and amount of water needed by plants. Crop Water Stress Index (CWSI) is used for monitoring and quantifying water stress as well as for irrigation scheduling. This study was conducted for the purpose of determining the Maize (SC-701) irrigation Scheduling, use of leaf temperature in the north of Isfahan, Iran, in the crop year 2013, with five irrigation areas, where the amount of Total Available Water (TAW) was 35, 65, 75, $85,100 \%$ respectively, in four replications. Results revealed that in return of TAW from 35 to $100 \%$, Leaf and air temperature difference (Tl-Ta) reached $4{ }^{\circ} \mathrm{C}$. CWSI rose about three times. CWSI in the day before the irrigation in treatment $\mathrm{T} 1$ and $\mathrm{T} 5$ was about 0.12 and 0.46 , respectively. The results revealed that non-stress equation for corn in the T3 (75\% TAW), was $\left(T_{c}-T_{a}\right)_{l . l}=-1.4101 V P D-1.7105$ and stress equation was completely fixed and is equal to 2.3. CWSI index is based on irrigation planning and it was 0.24 . Examining yield results revealed that irrigation scheduling in this area should be done by treatment at $75 \%$ TAW.
\end{abstract}

Keywords: deficit irrigation, leaf surface temperature, total available water, soil water deficit

\section{Introduction}

Nowadays, the world is facing with increasing population and demand for food as well as shortage of fresh water supplies (Zhang et al., 2016). Deficit irrigation (DI) and urban wastewater utilization are two management solutions for the purpose of reducing fresh water consumption in agriculture. Due to the shortage of irrigation water resources as well as the increase of the area under cultivation, farmers in northern part of Isfahan (viz., Borkhar province), Iran, employ these strategies. Precise irrigation planning could be of help in preventing water stress and optimum performance in plants. Water stress is considered one of the most important plant stresses, which is the most common and limiting factor for yield (Jackson et al., 1981; Scherrer et al., 2011; Zia et al., 2013). The intensity of water stress depends on the time and duration of the irrigation. In view of this, proper methods are needed to classify the water needed for plants in a spatial and temporal manner, and to consider the economic and environmental benefits (Herwitz et al., 2004; Taghvaeian et al., 2013).

Irrigation scheduling methods can be divided into three categories, namely, the use of water billing, the use of soil profiles, and the use of plant profiles. In this method, water balance is taken into account. Above all, irrigation is usually done when an acceptable amount of available soil water (i.e., readily available water) is used by the plant. Identifying the amount of available soil water for use depends on a variety of 
factors, such as plant type, physical, and chemical features of the soil. Along these lines, researchers have tried to employ methods that use all the parameters affecting evapotranspiration and water absorption to select a more proper management method. In this regard, the water stress of plants with several indices has been investigated. To compute these indices, it seems necessary to measure the temperature of the leaf surface and air.

Since 1970, canopy temperature has been accepted as an indicator of water stress because plants under stress, close their stomata for preserving water and reducing stomatal conduction, decreasing transpiration, and increasing leaf temperature (Ballester et al., 2013; Grant et al., 2006; Idso et al., 1977; Jones, 1999; Leinonen and Jones, 2004; Rodriguez et al., 2005). The relationship between air and canopy temperature has become more variable under water deficits (Mahan et al., 2012; Jackson et al., 1981). In this way, the use of canopy temperature to assess plant growth and development in the case of limited water access may be more reliable than air temperature alone (Mahan et al., 2014).

In addition, Tc can deviate significantly from Tair (Siebert et al., 2014; Rezaei et al., 2015). For instance, when soil is wet, as after a rainfall or irrigation, Tc may be several degrees cooler than the air. In opposition, with a dry soil profile, canopies can be several degrees warmer than the air owing to the shrinkage of transpiration rates associated with stomata closure under water deficit (Clawson et al., 1988; Wall et al., 2006) However, low transpiration rates can also take place when soils are wet, to be precise, when the air-canopy vapour pressure deficit (VPD) is low as it is in the case of humid-cool conditions. In addition, weather variables such as the amount of incident solar radiation and wind speed (which drives advection) can exert a large direct impact on Tc through the heat balance of the crop surface (Monteith and Unsworth,1990): and also indirectly through their influence on crop water use.

One of the most reliable indicators is the crop water stress index (CWSI). Several studies have been conducted on irrigation scheduling using leaf surface temperature measurements. (Candogan et al., 2013; Orta et al., 2003). The difference in air temperature and leaf area were calculated from the difference in vapour pressure for different irrigation treatments in soybean and watermelon plants. And sorghum in different irrigation systems was studied by O'Shaughnessy et al. (2010) and the crop water stress index (CWSI) was calculated.

Alderfasi and Nielsen (2001) examined the use of water stress index on wheat in Colorado, USA, and concluded that the plant water stress index is a useful tool for evaluating the condition of winter wheat. The water stress index of plants is also employed to identify the irrigation time and evaluation of water status in plants. Mangus et al. (2016) examined the water stress index of corn in four stages of plant growth; their results showed that in the third stage of corn growth (i.e., in the flowering stage) the surface temperature of the leaf is higher and the plant uses the most energy for cob growth and thus transpiration from the plant shrinks. Their results indicated that reduced transpiration and water absorption gave rise to an increase in temperature of leaf surface. It should also be mentioned that in the previous research, the use of the CWSI in irrigation treatments, as well as relative humidity and leaf area temperature were measured less. Measuring the potential of water in the planting environment due to factors such as root conditions and lack of steam pressure, the presence of water at any potential cannot guarantee the water absorption by the plant. To this end, the use of available water in leaf and leaf surface temperature were considered as an indicator. 
Based on the aforementioned studies, this study sought to compute the water stress index (CWSI) of the plant using the Idso method and plotting the lower and upper base line for maize (Single Crossover 701) under irrigation treatments in the climate of North Isfahan in order to identify irrigation time.

\section{Materials and method}

This study was carried out in Borkhar province, north of Isfahan, Iran, during the crop year of 2013 . The area is located at $32^{\circ} 47^{\prime}$ and $51^{\circ} 45^{\prime}$ longitude and latitude. The altitude of the area is $1950 \mathrm{~m}$ (Fig. 1). The weather condition of Borkhar is warm and dry, and the moisture content in the air is an average of $35 \%$, and the maximum evapotranspiration (ETO) is $7 \mathrm{~mm} \mathrm{day}^{-1}$. The weather conditions of the area during the growing season of corn are presented in Table 1. The physical and chemical properties of the tested soil are also shown in Table 2. Soil texture was measured with the method of the United States Department of Agriculture (USDA), soil acidity was recorded with a $\mathrm{pH}$ meter, and the electrical conductivity of soil with an electric conductivity meter.

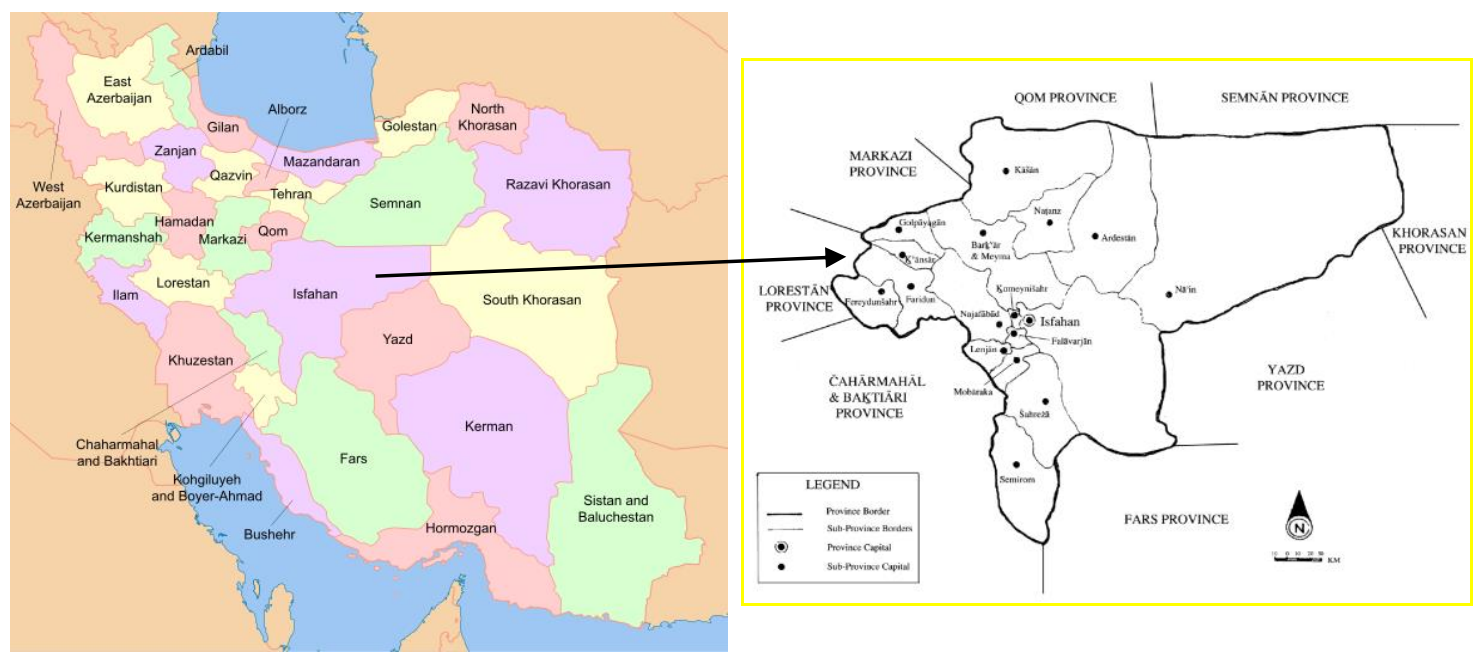

Figure 1. Area of study

Single Cross maize 701 (SC-701) was selected as an appropriate plant. The growth period of corn was 125 days. It was planted in the crop year 2013, June 27, was harvested in October 29. According to the soil test, $8-10 \mathrm{~kg} /$ ha triple phosphate fertilizer ( $46 \%$ phosphorus) was used manually in each plot at planting time. Fifty $\mathrm{kg} / \mathrm{ha}$ of ammonium nitrate was used along with irrigation water. Ammonium nitrate was mixed with irrigation water at the farm. Cruising herbicides four lit/ha on July 20 and Lasso herbicides at 20 lit/ha on August 17.

Regarding the pilot study and measurement of parameters, each was done in an area of $500 \mathrm{~m}^{2}$ in the farm. The maize crops were cultivated within $0.75 \mathrm{~m}$ between rows and $12 \mathrm{~cm}$ between the bushes, when the leaf of the plants reached a level that could be measured, data collection was started. The measurement was done in a period of 50 days. Measurements were done between two irrigations (on sunny days) every hour from 8 a.m. to 6 p.m. Relative humidity (RH), air temperature (Ta), and leaf area 
temperature (TL) were measured near the leaf area and Soil Moisture (SM) was measured at the level of the plant shadow.

Table 1. Weather during the maize growing periods in 2013

\begin{tabular}{c|c|c|c|c|c}
\hline Month (Year) & $\begin{array}{c}\text { Rainfall } \\
(\mathbf{m m})\end{array}$ & $\begin{array}{c}\text { Maximum } \\
\text { temperature } \\
\left({ }^{\circ} \mathbf{C}\right)\end{array}$ & $\begin{array}{c}\text { Minimum } \\
\text { temperature } \\
\left({ }^{\circ} \mathbf{C}\right)\end{array}$ & $\begin{array}{c}\text { Maximum } \\
\text { relative } \\
\text { moisture (\%) }\end{array}$ & $\begin{array}{c}\text { Minimum } \\
\text { relative } \\
\text { moisture (\%) }\end{array}$ \\
\hline June 2013 & 0.0 & 40.0 & 11.8 & 34.0 & 3.0 \\
July 2013 & 0.0 & 41.1 & 11.8 & 43.0 & 3.0 \\
August 2013 & 0.0 & 36.5 & 8.8 & 41.0 & 3.0 \\
September 2013 & 0.0 & 33.0 & 3.0 & 81.0 & 3.0 \\
October 2013 & 0.0 & 27.0 & 2.9 & 87.0 & 3.0 \\
\hline
\end{tabular}

Table 2. Physical and chemical properties of soil

\begin{tabular}{c|c|c|c|c|c|c|c|c|c}
\hline $\begin{array}{c}\text { Depth } \\
(\mathbf{c m})\end{array}$ & \% Clay & \%Silt & \%Sand & Text. & $\begin{array}{c}\text { EC } \\
\left(\mathbf{D s ~ m}^{-1}\right)\end{array}$ & $\begin{array}{c}\mathbf{N} \\
(\boldsymbol{\%})\end{array}$ & $\begin{array}{c}\mathbf{P} \\
\left(\mathbf{M g ~ k g}^{-1} \mathbf{a . v . a}\right)\end{array}$ & $\begin{array}{c}\mathbf{K} \\
\left(\mathbf{M g ~ k g}^{-1} \mathbf{a . v . a}\right)\end{array}$ & PH \\
\hline $0-30$ & 36 & 46 & 29 & CL & 3.5 & 0.1 & 40 & 423 & 8.2 \\
$30-60$ & 38 & 46 & 16 & Si.CL & 2.6 & 0.03 & 6.7 & 298 & 8.4 \\
\hline
\end{tabular}

Therefore, the plant was randomly selected and the surface temperature of the leaf was measured with an infrared thermometer from four directions and the average was recorded. In the Infrared thermometer model Testo 625 with $\pm 0.1{ }^{\circ} \mathrm{C}$ accuracy the ratio of the distance to the measurement slot was 1:8 (Fig. 2c). The measurement was done at a distance of $30 \mathrm{~cm}$ from the target (about $6 \mathrm{~cm}$ in diameter) and at a range of 10 to 20 degrees from the horizon (Jun and Dimer, 1999). Relative humidity of air (RH) was measured with humidity, and a relative humidity was recorded at 1 to $2 \mathrm{~cm}$ from the leaf area, where the temperature was measured (see Fig. 2d). Soil Moisture (SM) was measured at the surface of the plant shadow and at a depth of $30 \mathrm{~cm}$ from the root with a soil moisture meter or TDR produced by FIELDSCOUT (see Fig. $2 a, b$ ). The Vapour Pressure Deficit (VPD) was determined according to Equation 1 using air temperature and relative humidity (Monteith and Unsworth, 2013).

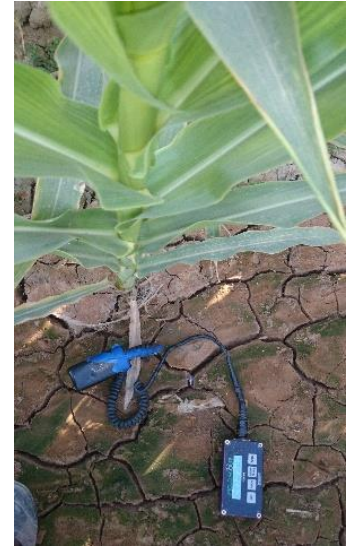

(a)

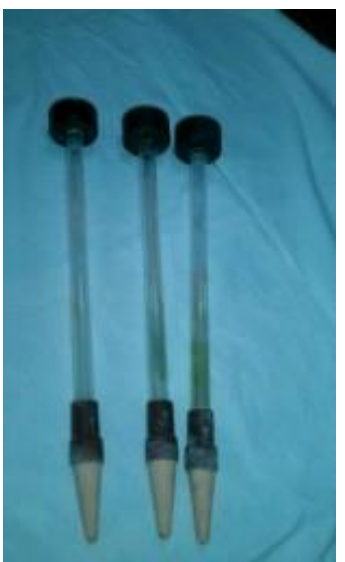

(b)

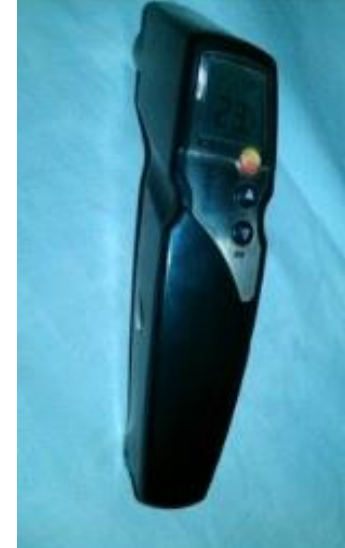

(c)

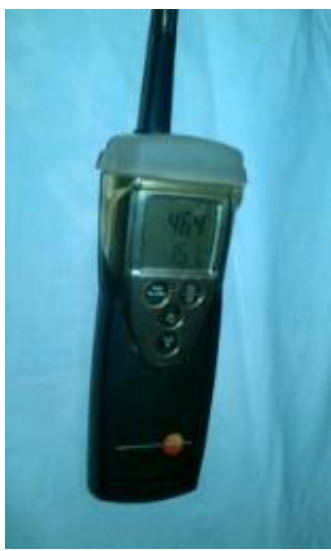

(d)

Figure 2. Measurement devices 
The water stress index of CWSI plant was taken into consideration on the basis of the linear relationship, during daytime and under homogeneous conditions (daylight or cloudy) between leaf surface temperature and temperature (TL-Ta) and VPD steam shortage for a well-irrigated product with the rate of potential transpiration (Idso et al., 1981). After calculating the air temperature and relative humidity, the shortage of VPD vapour pressure was determined with Equation 1, (Monteith and Unsworth, 2013). The difference in temperature between leaf and air was measured by the VPD saturation vapour pressure deficiency of more than $100 \mathrm{~W} \mathrm{m-}{ }^{2}$ solar radiation. The deficiency of VPD saturation vapour pressure is defined as follows (Eq. l):

$$
\mathrm{VPD}=\left(1-\left(\frac{R H}{100}\right) \times\left(0.6108 \times 10^{(7.5 \times T a / 237+T a}\right)\right)
$$

Where Ta: air Temperature $\left({ }^{\circ} \mathrm{C}\right)$, RH: Relative humidity (\%), VPD: Vapour pressure deficit $(\mathrm{kPa})$.

The shortage of VPD saturation vapour pressure was used to calculate the NWSB water stress baseline. The bottom line (without water stress NWSB) is a special feature of each plant and represents the conditions wherein the plant has no limitations in terms of water supply from the root zone, and evapotranspiration is within the maximum range. AIDS has introduced the lower-tension line as follows (Eq. 2; Idso et al., 1982):

$$
\left(T_{l}-T_{a}\right)_{u}=a-b \times V P D
$$

In this regard, $\left(T_{l}-T_{a}\right)_{u}$ is the difference between the surface temperature of the leaf and the air in the lower base line conditions $\left({ }^{\circ} \mathrm{C}\right)$, a width from the origin and $\mathrm{b}$ : the linear gradient. Experimental coefficients of non-stressed basal line are measured through temperature of leaf area in five irrigation treatments (Table 3).

The highest water stress line (full stress) is computed irrespective of the vapour pressure shortage and is derived from Equation 3 (Idso et al., 1982).

$$
\left(T_{l}-T_{a}\right)_{w l}=h
$$

h: constant value in degrees Celsius, (Tl-Ta) $)_{\mathrm{ul}}$ difference between the surface temperature of the leaf and the air in the upper base line conditions $\left({ }^{\circ} \mathrm{C}\right)$.

Previous studies suggest that for the empirical determination of the non-stressed baseline and water stress baseline, directly from pure radiation, stomatal resistance, and micro-climatic conditions of the product, is an influential technique for the identification of CWSI (Ballester et al., 2013). The CWSI actual temperature was computed using the equation (Eq. 4) (Idso et al., 1981; Jackson et al., 1981).

$$
\text { CWSI }=\frac{\left(T_{l}-T_{a}\right)_{m}-\left(T_{l}-T_{a}\right)_{u}}{\left(T_{l}-T_{a}\right)_{u l}-\left(T_{l}-T_{a}\right)_{u}}
$$

$(\mathrm{Tl}-\mathrm{Ta})_{\mathrm{m}}$ : Leaf and air temperature difference is the day the CWSI target is set for that day. 
Table 3. Date and depth of irrigation water $(\mathrm{mm})$ for different irrigation treatments (T1-T5) in 2013

\begin{tabular}{c|c|c|c|c|c}
\hline & T1 & T2 & T3 & T4 & T5 \\
\hline 28 June & 105 & 105 & 105 & 105 & 105 \\
5 July & 60 & 60 & 60 & 60 & 60 \\
26 July & 120 & 120 & 120 & 120 & 120 \\
3 August & 115 & 115 & 115 & 115 & 115 \\
11 August & 130 & 130 & 130 & 130 & 130 \\
20 August & - & - & - & - & 70 \\
23 August & - & - & 70 & 70 & - \\
25 August & - & 70 & - & - & 70 \\
28 August & 70 & - & - & 70 & - \\
4 September & - & - & 70 & - & 70 \\
7 September & - & 70 & - & 70 & - \\
20 September & - & - & - & - & 70 \\
27 September & 70 & - & 70 & 70 & - \\
4 October & - & 70 & - & - & 70 \\
9 October & - & - & 70 & 70 & 70 \\
Total & 670 & 740 & 810 & 880 & 950 \\
\hline
\end{tabular}

Soil moisture content is used to identify the time and amount of irrigation regarding non-stressed water treatment. In view of that, first, the amount of moisture absorbed by the plant $(\theta \mathrm{CEC})$ needs to be calculated (Eq. 5), and then whenever humidity reaches its limit, irrigation is done; that is to say, as soon as the daily moisture content ( $\theta i)$ reaches the limit of the plant capability of absorbing moisture $(\theta \mathrm{CEC})$, irrigation is done. Equation 6 is used to identify the depth of irrigation water. Admissible moisture discharge management rate is $30 \%$.

$$
\theta_{C E C}=\theta_{F C}-\left(\theta_{F C}-\theta_{P W P}\right) \times M A D
$$

where $\theta \mathrm{CEC}$ is the volumetric moisture content of the plant, $\theta \mathrm{FC}$ is the volumetric moisture content of the soil at the capacity limit, and OPWP is the volumetric moisture content of the soil at the point of permanent wilting point, and MAD is the maximum moisture discharge coefficient.

$$
d_{n}=\left(\theta_{F C}-\theta_{P W P}\right) \times M A D \times D_{r z}
$$

in which, dn is the depth of irrigation water $(\mathrm{mm})$ and Drz is the depth of the root development area $(\mathrm{mm})$. The amount of water consumed by the plant was calculated by measuring the water balance components according to Equation 7.

$$
I=\left(E T_{C}+D_{d}+R_{0}\right) \pm \Delta S
$$

in which, I is the irrigation water depth $(\mathrm{mm})$, ETC is plant evapotranspiration $(\mathrm{mm})$, $\mathrm{Dd}$ is drainage depth $(\mathrm{mm}), \mathrm{R} 0$ is runoff depth $(\mathrm{mm})$, and $\Delta \mathrm{S}$ is soil moisture storage variation $(\mathrm{mm})$. Irrigation is done with the customary manner when water is easily used 
by the plant. In water discharge, the criterion for measuring water stress is the presence of water in the planting environment. Employing direct measurement of the moisture content of the plant organs, in this study, the leaf water potential or leaf surface temperature as a water stress index, the results were compared with the blue-shoe method.

Irrigation treatments were chosen regarding the time and intensity of the stress, both of which influence the yield of the crop, which included five treatments (T1-T5) at $35 \%, 65 \%, 75 \%, 85 \%$ and $100 \%$ TAW and four replicates. T1 and T5 treatments had the minimum and maximum irrigation water consumption (Table 3). Moisture content were measured with TDR, which measures soil moisture at a depth of $35 \mathrm{~cm}$. As to the calculation of TDR, three tensiometers (block 1, 3, and 5) were employed in different fields of the farm. The water potential was identified in a planting environment with tensiometers that degree of cryopreservation was 0 to $600 \mathrm{~mm}$. The suction obtained from the tensiometer reading was converted into soil moisture content (at a probability level of 5\%) using the Van Genuchten equation (Eqs. 8 and 9). The relationship between moisture and suction in Figure 1, shows its components for experimental farm soil according to the following equations:

$$
\begin{gathered}
m=1-\frac{1}{n} \\
\theta=\theta_{r}+\frac{\theta_{s}-\theta_{r}}{\left[1+(\alpha h)^{n}\right]^{m}}
\end{gathered}
$$

where $\theta \mathrm{r}$ is residual moisture, $\theta \mathrm{s}$ is saturated moisture, $(\alpha, \mathrm{n}$, and $\mathrm{m})$. Parameters of the form L: porosity correlation index and K_s: saturation hydraulic conductivity, which equal to $0.08373,0.4613,0.0094,0.4636$, and 0.3168 .

The analysis of CWSI and the result of the efficiency of the product was done with SPSS and Excel.

\section{Results and discussion}

Based on the equations presented in the previous section and the field data, in the days after irrigation, the bases without water stress were calculated in real conditions of the farm (Figs. 3 and 4). The regression curve was fitted in each treatment and the lower and upper base line equations are presented in Table 4.

The greatest number of data in the range of 1 to 6 kilopascals relates to the lack of air vapour pressure. Days after irrigation with increasing air temperature from morning to evening, with increasing air pressure and increasing evaporation and transpiration, water flow from root to leaf is always maintained and the plant is kept cool. This process continues until the plant can absorb water from the soil. But when the plant cannot absorb soil moisture, it becomes watery and the irrigation time is reached, especially at noon hours, with the increasing lack of air vapour pressure and increasing air temperature, the temperature difference between the leaf surface and air decreases and the leaf temperature increases. Base lines based on stress and non-stress conditions for T5 to T1 treatments were used to calculate CWSI. The amount of $\mathrm{R}^{2}$ in Figure 3 and Table 4 shows the correlation between the temperature difference of the air and the leaf area against the difference in vapour pressure. The lowest amount of $R^{2}(0.665$ and 
0.652) was observed in both $\mathrm{T} 1$ and $\mathrm{T} 2$ treatments. As a result of the decline of water absorption and transpiration, the leaf surface temperature is higher and the difference in leaf and air temperature is positive. The highest amount of $\mathrm{R}^{2}(0.70$ and 0.74$)$ was related to $\mathrm{T} 4$ and $\mathrm{T} 5$ treatments, and refers to increased water absorption and transpiration. As soon as the leaf surface temperature decreased, and the difference between the surfaces temperature of the leaves and the air was negated the yield of the product increased. The results of Idso et al. (1977) showed that when the plant does not have water deficit, the difference between the plant's green cover $\left(T_{c}\right)$ and the temperature (Ta) is negative. When the plant is under intense tension, the difference between the temperature of the plant and air green cover somewhat positive.

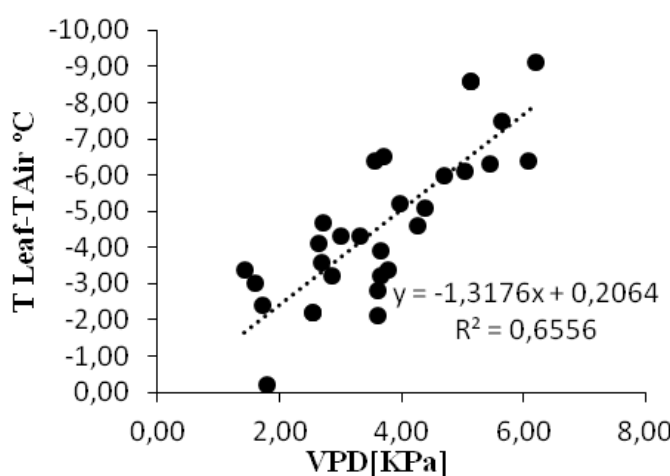

(T1)

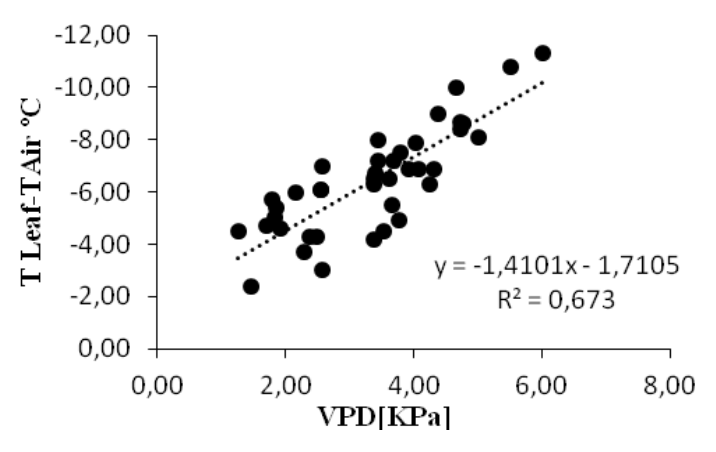

(T3)

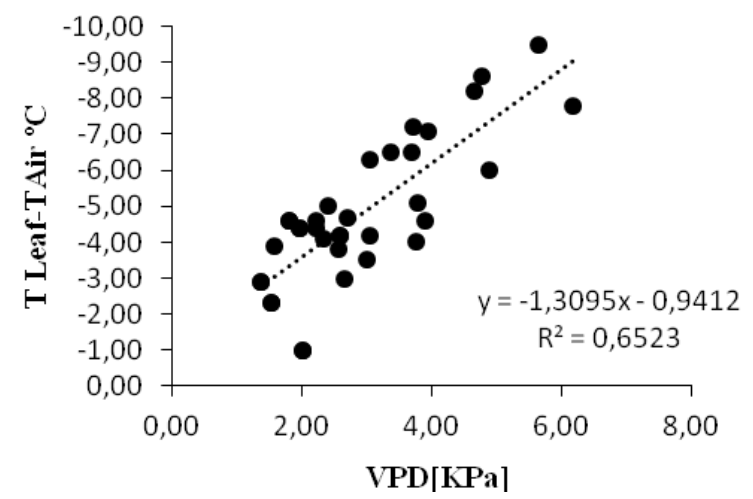

(T2)

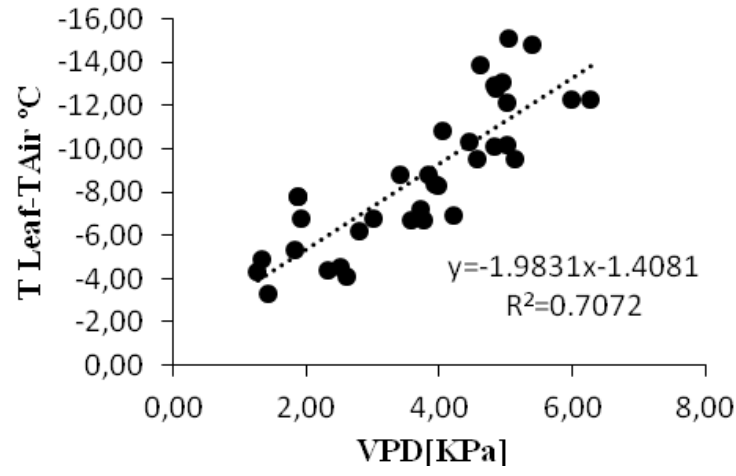

(T4)

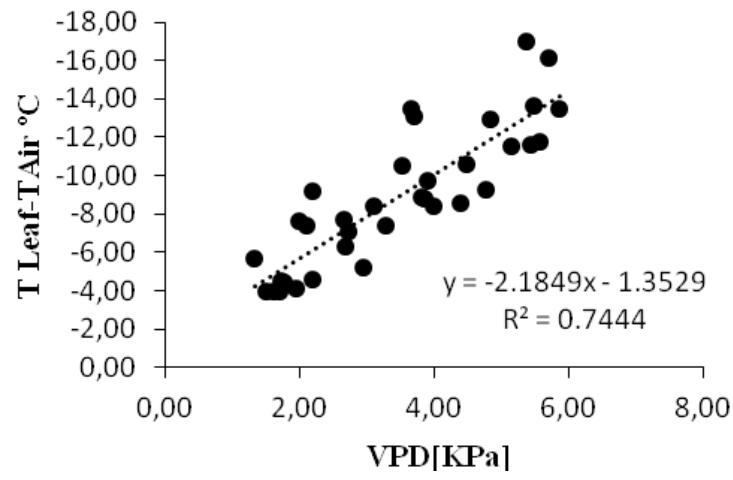

(T5)

Figure 3. Position of the upper base lines under each treatment 


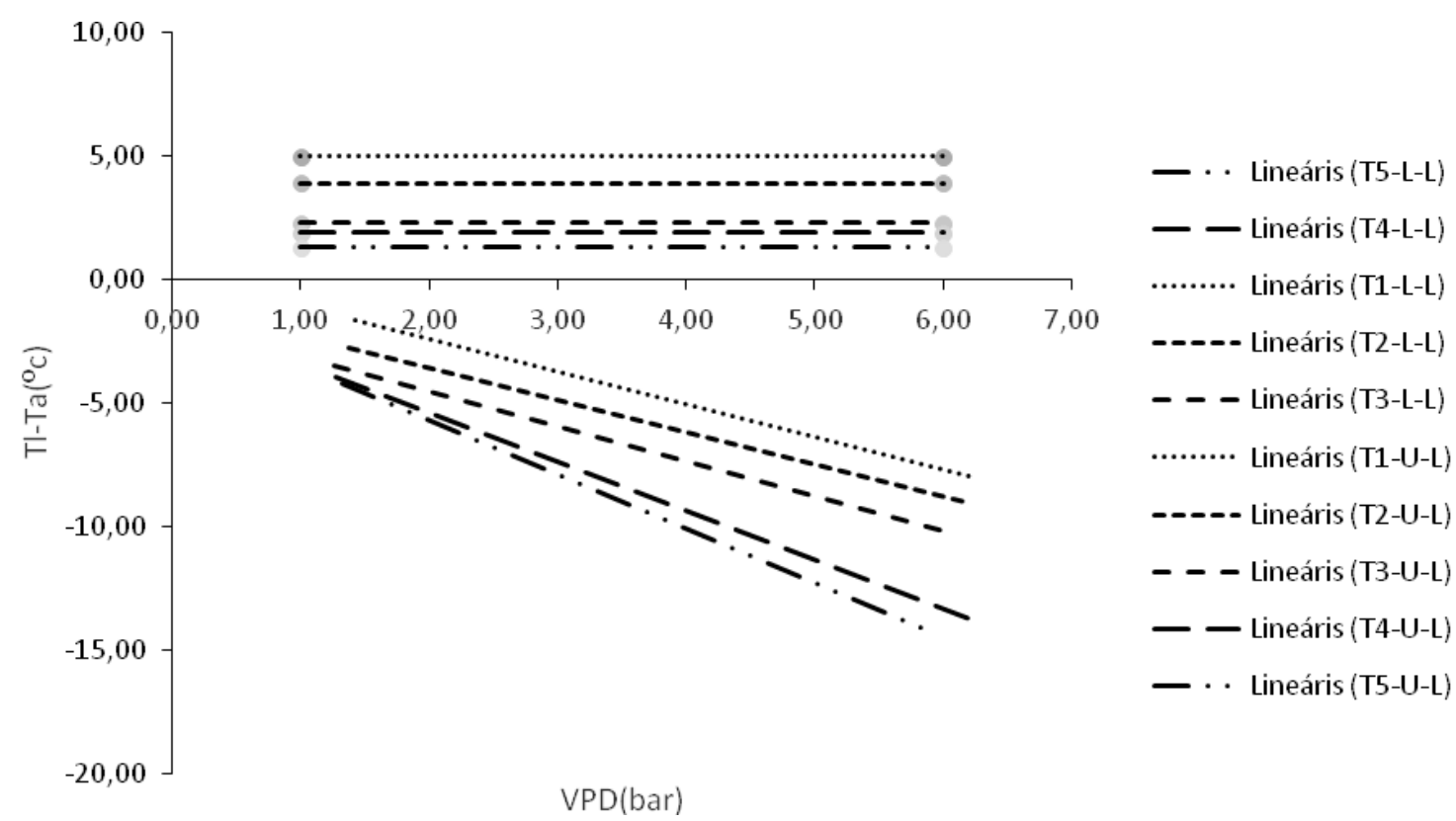

Figure 4. Position of the upper and lower base lines under each treatment. (T: treatment number, $U$-L: upper base line, L-L: bottom line)

Table 4. Estimation of leaf and air temperature difference versus saturated vapor pressure

\begin{tabular}{c|c|c|c}
\hline Treatment & The base line equation above & Bottom line equation & R2 \\
\hline $\mathrm{T} 1$ & $\left(T_{c}-T_{a}\right)_{u l}=5$ & $\left(T_{c}-T_{a}\right)_{l . l}=-1.3176 \mathrm{VPD}+0.2064$ & 0.66 \\
$\mathrm{~T} 2$ & $\left(T_{c}-T_{a}\right)_{u l}=3.9$ & $\left(T_{c}-T_{a}\right)_{l . l}=-1.3095 \mathrm{VPD}-0.9412$ & 0.65 \\
$\mathrm{~T} 3$ & $\left(T_{c}-T_{a}\right)_{u l}=2.3$ & $\left(T_{c}-T_{a}\right)_{l . l}=-1.4101 \mathrm{VPD}-1.7105$ & 0.67 \\
$\mathrm{~T} 4$ & $\left(T_{c}-T_{a}\right)_{u l}=1.9$ & $\left(T_{c}-T_{a}\right)_{l . l}=-1.9831 V P D-1.4081$ & 0.70 \\
$\mathrm{~T} 5$ & $\left(T_{c}-T_{a}\right)_{u l}=1.3$ & $\left(T_{c}-T_{a}\right)_{l . l}=-2.1849 \mathrm{VPD}-1.35292$ & 0.74 \\
\hline
\end{tabular}

The data in Table 4 and Figure 3 indicate the position of the upper base lines under each treatment and Figure 4 indicates that with increasing water stress, the upper and lower base lines are displaced. As a result of increasing water stress from T5 to T1, the linear gradient tilt (Tl-Ta) and VPD has fallen below the baseline from +0.2046 to 1.3529. On the other hand, as a result of increasing water stress from T5 to T1, the tensile base line has also risen from 1.3 to 5. Mangus et al. (2016) obtained the water stress base line at different stages of corn growth, equal to 5. Alderfasi and Nielsen (2001) presented the low-level wheat line equation at Colorado State University (Collins) $(\mathrm{Tc}-\mathrm{Ta})_{1.1}=0.41-1.5$ VPD. Mangus et al. (2016) presented the base-line equation as follows. Empirical leaf canopy and air temperature deficit versus VPD during (a) germination and seedling stage $(\mathrm{Tc}-\mathrm{Ta})_{1.1}=2.9491-3.3865 \mathrm{VPD}$, (b) rapid growth stage $(\mathrm{Tc}-\mathrm{Ta})_{1.1}=3.5164-3.3981 \mathrm{VPD}$, (c) reproductive stage $(\mathrm{Tc}-\mathrm{Ta})_{1.1}=$ 4.2097 - 2.7815 VPD, and (d) maturity stage (Tc-Ta) $)_{1.1}=4.2337-2.7367$ VPD.

The results showed that the line equations for the minimum stress of different products are similar in appearance, but the angle and width coefficients are not similar at the source. It is of note that even under different irrigation conditions and different 
irrigation treatments, a single equation cannot be proposed for a particular plant. Comparing the bottom line of corn in different treatments suggests this discussion.

Figure 4 shows a decrease (Tl-Ta) for increasing the VPD unit in each of the irrigation treatments. For instance, at a reduced steam pressure of $3 \mathrm{kPa}$, the variation in leaf and air temperature difference variations is shown in Table 5. Negative numbers indicate that the air temperature is higher than the surface temperature of the leaves, as well as for the reduction of the drainage allowed the humidity to rise from $35 \%$ to $100 \%$ (TAW), the difference in leaf and air temperature is around $3{ }^{\circ} \mathrm{C}$.

Table 5. Changes (Tl-Ta) to changes VPD in the (T1-T5)

\begin{tabular}{c|c|c|c|c|c}
\hline \multirow{2}{*}{ VPD (K Pa) } & \multicolumn{5}{|c}{ Treatment } \\
\cline { 2 - 6 } & T1 & T2 & T3 & T4 & T5 \\
\hline 2 & -2.4 & -3.5 & -4.5 & -5.4 & -5.7 \\
3 & -3.7 & -4.9 & -5.9 & -7.3 & -8.0 \\
4 & -5.1 & -6.2 & -7.3 & -9.3 & -10.0 \\
5 & -6.3 & -7.4 & -8.7 & -11.3 & -12.2 \\
6 & -7.7 & -8.8 & -10.1 & -13.3 & -14.5 \\
\hline
\end{tabular}

The (CWSI) was calculated on the basis of the lower and upper base line equations in Equation 4, and the value of CWSI was calculated on the day after irrigation under each treatment. The average leaf and air temperature, as well as the CWSI for each treatment and recurrence, are displayed in Table 6. Data from Table 6 disclose that with decreasing soil moisture, surface irrigation temperatures are rising in irrigation treatments, resulting in difference in leaf and air temperature. Because of irrigation at each turn, the irrigation is based on the desired treatment, so, the stress produced as a result of shortage of irrigation water increased the leaf area temperature and CWSI. According to the results of analysis of variance in Table 7, the effect of experimental treatments on CWSI is discussed in detail. The results of Table 7 of analysis of variance revealed that irrigation treatments have a significant effect on the CWSI at a one percent probability level. Comparison of CWSI data by Duncan test (see Table 8) for different irrigation treatments showed that there is a significant difference between treatments. By increasing the acceptable drainage from 35\% to $100 \%$, the CWSI increased from 0.07 to 0.44 (see Tables 7 and 8).

Table 6. Information needed to calculate CWSI

\begin{tabular}{c|c|c|c|c|c|c|c|c|c|c}
\hline \multicolumn{2}{c|}{ T1 } & \multicolumn{2}{c|}{ T2 } & \multicolumn{2}{c|}{ T3 } & \multicolumn{2}{c|}{ T4 } & \multicolumn{2}{c|}{ T5 } & \multirow{2}{*}{ Repeat } \\
\cline { 1 - 8 } CWSI & TL-TA & CWSI & TL-TA & CWSI & TL-TA & CWSI & TL-TA & CWSI & TL-TA & \\
\hline 0.39 & -2.6 & 0.16 & -3.5 & 0.13 & -5.7 & 0.07 & -10.4 & 0.06 & -11.7 & First repeat \\
0.45 & -2.4 & 0.19 & -3.2 & 0.14 & -5.6 & 0.09 & -10.2 & 0.08 & -11.5 & Second repeat \\
0.49 & -2.2 & 0.21 & -3 & 0.15 & -5.5 & 0.10 & -10 & 0.08 & -11.4 & Third repeat \\
0.43 & -2.5 & 0.18 & -3.3 & 0.14 & -5.6 & 0.07 & -10.1 & 0.07 & -11.4 & Fourth repeat \\
0.44 & -2.4 & 0.19 & -3.25 & 0.14 & -5.6 & 0.09 & 10.2 & 0.07 & -11.55 & Average \\
\hline
\end{tabular}


Table 7. Analysis of the variance of the CWSI in the experiment

\begin{tabular}{|c|c|c|c|}
\hline \multirow{3}{*}{ Sources of changes } & \multirow{3}{*}{ d.f. } & Before irrigation & After irrigation \\
\hline & & \multicolumn{2}{|c|}{ Average of squares } \\
\hline & & CWSI & CWSI \\
\hline Soil moisture & 4 & $0.049 * *$ & $0.07 * *$ \\
\hline Repeat & 3 & $0.00 \mathrm{~ns}$ & $0.003 * *$ \\
\hline Error & 9 & 0.001 & 0.00 \\
\hline
\end{tabular}

$\mathrm{ns}, * *$ and *, respectively, are not significant and significant at the probability level of 1 and $5 \%$

Table 8. Comparison of CWSI means before and after irrigation, using Duncan test

\begin{tabular}{c|c|c}
\hline \multirow{2}{*}{ Treatment } & Before irrigation & After irrigation \\
\cline { 2 - 3 } & \multicolumn{2}{|c|}{ CWSI } \\
\hline T1 & $0.47 \mathrm{~d}$ & $0.45 \mathrm{~d}$ \\
T2 & $0.30 \mathrm{c}$ & $0.19 \mathrm{c}$ \\
T3 & $0.24 \mathrm{~b}$ & $0.14 \mathrm{~b}$ \\
T4 & $0.21 \mathrm{~b}$ & $0.09 \mathrm{a}$ \\
T5 & $0.12 \mathrm{a}$ & $0.08 \mathrm{a}$ \\
\hline
\end{tabular}

The same letters do not differ significantly from each other. *Treatments were introduced in the materials and methods

Irmak et al. (2002) and Greaves and Wang (2017) reported similar observations in CWSI trend in the cases of water deficit stress. For irrigation scheduling, the actual stress before irrigation, leaf area temperature changes (each of the treatments under stress) were used. The average leaf and air temperature and CWSI for the days before irrigation in each treatment type and replicate are displayed in Table 9. According to the results of variance analysis of Table 7, the effect of experimental treatments on CWSI in the days before irrigation is discussed in details below. The results of analysis of variance show that irrigation treatments have a significant effect on the CWSI at a one percent probability level. Comparison of CWSI means by Duncan test (1977) for different irrigation treatments showed that there is a significant difference between treatments. As a result of increasing drainage volumes from $37 \%$ to $100 \%$, the CWSI increased from 0.12 to 0.46 . The crop water stress index (CWSI) is closely related to extractable water in the root zone, making it an effective parameter for identifying the severity of crop water stress. For the purpose of this study, the following threshold was adopted to indicate the severity of water stress imposed by the irrigation treatments: CWSI values $\leq 0.2$ little to no water stress, $0.2<$ CWSI values $\leq 0.4$ mild to moderate water stress and CWSI $>0.4$ severe water stress. The threshold values adopted in the previous studies were appropriate for the severity designated (Irmak et al., 2000; Candogan et al., 2013). The results of analysis of variance of yields of irrigation treatments are displayed in Table 10. Results showed that there was no significant difference between yields of T3 to T5 treatments. The results of comparison of yields in irrigation treatments for corn are presented in Table 11. In this research, the highest grain yield was 9.6 ton $^{-1}$ for $\mathrm{T} 5$ treatment and the lowest grain yield was 7.1 ton $\mathrm{h}^{-1}$ for $\mathrm{T} 1$ treatment. Table 11 shows the results of variance analysis for grain yield between treatments and different years, which has a significant difference at $5 \%$ probability level (see Table 10). Corn plant is relatively tolerant in 
vegetative stage and handles water shortage well, but the highest losses take place owing to blue stress during flowering period. Plant height was measured at the end of vegetative growth stage. The maximum height of $178 \mathrm{~cm}$, belonging to T5 treatment and the lowest height of $165 \mathrm{~cm}$ occurred in T1 treatment (see Table 11). The results of analysis of variance showed that the effect of irrigation treatments was not significant at 5\% probability level Table 10. Comparison of yield of treatments showed that the best irrigation time needs to be based on T3 treatment, which in addition maintains the optimum performance of water saving in irrigation. Also, the water stress index of the plants in the days before irrigation in T1 T4, T3, T2 and T5 treatments was $0.12,0.21$, $0.24,0.30$ and 0.46 respectively. As a result, the best irrigation time is when the CWSI is less than 0.24. Irrigation scheduling based on the equation Idso (1981) states that the maximum stress does not exceed 0.24. To identify the irrigation time, the surface temperature of the leaf is measured at 12 to 15 hours, and then, according to Equations 14 , the value of the CWSI is calculated. If the calculated value is greater than 0.24 , irrigation should be carried out. These findings bear testimony to those reported by Yazar et al. (1999) who observed that minimal biomass yield reductions occur at a threshold CWSI value of 0.33 or less for maize. Significant reduction in biomass due to crop water stress have also been reported in other studies (Omidi et al., 2012; Djaman et al., 2013; Greaves and Wang, 2017). The high productivity was associated with DI in maize production, as long as water application amount is adequate to keep soil moisture below the stress threshold and irrigation timing cannot impose stress during the critical growth period, which can be attributed to the stimulated physiological response of the crop after soil drying episodes leading to compensation or overcompensation in plant growth and grain yield (Liu et al., 2010).

Table 9. Information needed to calculate CWSI

\begin{tabular}{c|c|c|c|c|c|c|c|c|c|c}
\hline \multicolumn{2}{c|}{ T1 } & \multicolumn{2}{c|}{ T2 } & \multicolumn{2}{c|}{ T3 } & \multicolumn{2}{c|}{ T4 } & \multicolumn{2}{c}{ T5 } & \multirow{2}{*}{ Repeat } \\
\cline { 1 - 8 } CWSI & TL-TA & CWSI & TL-TA & CWSI & TL-TA & CWSI & TL-TA & CWSI & TL-TA & \\
\hline 0.43 & -0.2 & 0.34 & -1 & 0.24 & -3.5 & 0.23 & -4.5 & 0.11 & -6.3 & First repeat \\
0.45 & -0.0 & 0.29 & -1.4 & 0.26 & -3.3 & 0.20 & -4.4 & 0.14 & -6.0 & Second repeat \\
0.52 & 1.0 & 0.27 & -0.8 & 0.21 & -3.7 & 0.29 & -4.1 & 0.12 & -6.2 & Third repeat \\
0.47 & 0.16 & 0.30 & -1.1 & 0.25 & -3.4 & 0.22 & -4.2 & 0.13 & -6.1 & Fourth repeat \\
0.46 & 0.26 & 0.30 & -1.06 & 0.24 & -3.5 & 0.21 & -4.33 & 0.12 & -6.16 & Average \\
\hline
\end{tabular}

Table 10. Analysis of variance of yield and grain yield of maize (ANOVA)

\begin{tabular}{c|c|c|c|c|c|c}
\hline \multirow{2}{*}{ Year } & \multirow{2}{*}{ Source of variation (SOV) } & \multicolumn{5}{|c}{ Mean squares } \\
\cline { 3 - 7 } & & d.f. & Wet yield & Dry yield & Plant height & Grain yields \\
\hline \multirow{3}{*}{2013} & Block & 3 & 161.82 & 16.68 & 31.95 & 1.18 \\
& Treatment & 4 & $315.00 \mathrm{~ns}$ & $23.05^{* *}$ & $97.18 \mathrm{~ns}$ & $4.21^{*}$ \\
& Error & 12 & 50.15 & 6.13 & 54.74 & 1.4 \\
& cv (coeff var) & & 8.00 & 9.58 & 4.27 & 13.93 \\
\hline
\end{tabular}

** and * are significantly different at 1 and $5 \%$ levels, respectively. ns: No significant differences at the $5 \%$ significance level 
Table 11. Average different treatments in Duncan

\begin{tabular}{c|c|c|c|c|c}
\hline Year & Treatment & $\begin{array}{c}\text { Wet yield } \\
\text { (ton ha-1) }\end{array}$ & $\begin{array}{c}\text { Dry yield } \\
\text { (ton ha-1) }\end{array}$ & $\begin{array}{c}\text { Plant height } \\
\text { (cm) }\end{array}$ & $\begin{array}{c}\text { Grain yields } \\
\text { (ton ha-1) }\end{array}$ \\
\hline \multirow{6}{*}{2013} & T1 & $77.8 \mathrm{c}$ & $22.0 \mathrm{c}$ & $165 \mathrm{ab}$ & $7.1 \mathrm{~b}$ \\
& $\mathrm{~T} 2$ & $80.3 \mathrm{bc}$ & $25.2 \mathrm{ab}$ & $176 \mathrm{ab}$ & $7.3 \mathrm{~b}$ \\
& $\mathrm{~T} 3$ & $91.0 \mathrm{ab}$ & $26.8 \mathrm{a}$ & $171 \mathrm{ab}$ & $9.2 \mathrm{a}$ \\
& $\mathrm{T} 4$ & $97.2 \mathrm{a}$ & $28.0 \mathrm{a}$ & $171 \mathrm{ab}$ & $9.3 \mathrm{a}$ \\
& T5 & $95.8 \mathrm{a}$ & $27.4 \mathrm{a}$ & $178 \mathrm{a}$ & $9.6 \mathrm{a}$ \\
& Avg & 88.4 & 25.9 & 172 & 8.5 \\
\hline
\end{tabular}

Means with the same letters within a season were not significantly different at the 5\% significance level

\section{Conclusions}

The decline of air vapour pressure during the growing season varies from 1 to 6.2 atmospheres. The low-base equation in irrigation treatments indicated that with the increase of VPD, the difference between leaf surface temperature and air temperature widened. The findings of this study revealed that reducing irrigation water increased the surface temperature of the leaf, increasing from $35 \%$ to $100 \%$ TAW, and the leaf surface temperature difference increased to about $4^{\circ}$. In this study, the CWSI was calculated in the days before irrigation in T1, T2, T3, T4 and T5 treatments, and its values were $0.12,0.21,0.24,0.30$ and 0.46 , respectively. The results also showed that with soil moisture change from 26 to 36 percent, the CWSI was about 3.5 times higher. Accordingly, the CWSI can be used to plan irrigation. Comparison of yield of treatments showed that the best irrigation time is based on T3 treatment and when CWSI is less than 0.24, in addition it maintains optimum performance of water saving in irrigation. The results also showed that with soil moisture change from 35 to $100 \%$, the CWSI was about 3.5 times higher. As a result, the CWSI can be used to plan irrigation.

Acknowledgements. This project was sponsored by Azad University of Science and Research Branch of Tehran and Azad University of Khorasgan, Isfahan, Iran and Isfahan Sepehr Damyaran Company.

\section{REFERENCES}

[1] Alderfasi, A. A., Nielsen D. C. (2001): Use of crop water stress index for monitoring water status and scheduling irrigation in wheat. - Agricultural Water Management 47: 69-75. https://doi.org/10.1016/S0378-3774(00)00096-2.

[2] Ballester, C., Jimenez-Bello, M. A., Castel, J. R., Intrigliolo, D. S. (2013): Usefulness of thermography for plant water stress detection in citrus and persimmon trees. Agricultural Water Management 168: 120-129. https://doi.org/10.1016/j.agrformet.2012.08.005.

[3] Candogan, B. N., Shncik, M., Buyukcangaz, H., Demirtas, C., Goksoy, T. A., Yazgan, S. (2013): Yield, quality and crop water stress index relationships for deficit-irrigated soybean [Glycine max (L.) Merr.] in sub-humid climatic conditions. - Agricultural Water Management 118: 113-121. https://doi.org/10.1016/j.agwat.2012.11.021.

[4] Clawson, K. L., Jackson, R. D., Pinter, P. J. (1988): Evaluating plant water stress with canopy temperature differences. - Agronomy Journal 81: 858-863. DOI: 10.2134/agronj1989.00021962008100060004x. 
[5] Djaman, K., Irmak, S., Rathje, W. R., Martin, D. L., Eisenhauer, D. E. (2013): Maize evapotranspiration, yield production functions, biomass, grain yield, harvest index, and yield response factors under full and limited irrigation. - American Society of Agricultural and Biological Engineers 56 (March 2013): 273-293. https://digitalcommon s.unl.edu/ bio sysengfacpub.

[6] Grant, O. M., Chaves, M. M., Jones, H. G. (2006): Optimizing thermal imaging as a technique for detecting stomatal closure induced by drought stress under greenhouse conditions. - Physiologia Plantarum 127: 507-518. https://doi.org/10.1111/j.13993054.2006.00686.x.

[7] Greaves, G. E., Wang, Y. M. (2017): The effect of water stress on radiation interception, radiation use efficiency and water use efficiency of maize in a tropical climate. - Turkish Journal of Field Crops 22: 114-125. DOI: 10.17557/tjfc.311904.

[8] Herwitz, S. R., Johnson, L. F., Dunagan, S. E., Higgins, R. G., Sullivan, D. V., Zheng, J., Lobitz, B. M., Leung, J. G., Gallmeyer, B. A., Aoyagi, M., Slye, R. E., Brass, J. A. (2017): Imaging from an unmanned aerial vehicle: agricultural surveillance and decision support. - Computers and Electronics in Agriculture 44: 49-61. https://doi.org/10.1016/j.compag.2004.02.006.

[9] Idso, S. B., Jackson, R. D., Pinter. P. J., Reginato, R. J., Hatfield, J. L. (1981): Normalizing the stress degree-day parameter for environmental variability. - Agricultural Meteorology 24: 45-55. https://doi.org/10.1016/0002-1571(81)90032-7.

[10] Idso, S. B., Jackson, R. D., Reginato, R. J. (1977): Remote sensing of crop yields. Science 196: 19-25. DOI: 10.1126/science.196.4285.19.

[11] Idso, S. B., Reginato, R. J., Radin, J. W. (1982): Leaf diffusion resistance and photosynthesis in cotton related to a foliage temperature based plant water stress index. Agricultural Meteorology 27: 27-34. https://doi.org/10.1016/0002-1571(82)90016-4.

[12] Irmak, A., Batchelor, W. D., Jones, J. W., Irmak, S., Paz, J. O., Beck, H. W., Egeh, M. (2002): Relationship between plant available soil water and yield for explaining soybean yield variability. - Applied Engineering in Agriculture 18: 471-482. DOI: 10.13031/2013.8748.

[13] Irmak, S., Haman, D. Z., Bastug, R. (1998): Determination of crop water stress index for irrigation timing and yield estimation of corn. - Agronomy Journal 92: 1221-1227. DOI: 10.2134/agronj2000.9261221x.

[14] Jackson, R. D., Idso, S. B., Reginato, R. J., Pinter Jr., P. J. (1981): Canopy temperature as a drought stress indicator. - Water Resources Research 17: 1133-1138. https://doi.org/10.1029/WR017i004p01133.

[15] Jones, H. G. (2002): Use of thermography for quantitative studies of spatial and temporal variation of stomata conductance over leaf surfaces. - Plant, Cell \& Environment 22: 1043-1055. https://doi.org/10.1046/j.1365-3040.1999.00468.x.

[16] Leinonen, I., Jones, H. G. (2004): Combining thermal and visible imagery for estimating canopy temperature and identifying plant stress. - Journal of Experimental Botany 55: 1423-1431. https://doi.org/10.1093/jxb/erh146.

[17] Liu, Y., Yang, S., Li, S., Chen, X., Chen, F. (2010): Growth and development of maize (Zea mays L.) In response to different field water management practices: Resource capture and use efficiency. - Agricultural and Forest Meteorology 150: 606-613. https://doi.org/10.1016/j.agrformet.2010.02.003.

[18] Mahan, J. R., Young, A. W., Payton, P. (2012): Deficit irrigation in a production setting: canopy temperature as an adjunct to ET estimates. - Irrigation Science 30: 127-137. http://dx.doi.org/10.1007/s00271-011-0269-1.

[19] Mahan, J. R., Young, A., Payton, P., Bange, M., Stout, J. (2014): Effect of differential irrigation on accumulation of canopy temperature-based heat units in cotton. - Journal Cotton Science 18: 129-136. https://www.researchgate.net/publication/284415252.

[20] Mangus, D. L., Sharda, A., Zhang, N. (2016): Development and evaluation of thermal infrared imaging system for high spatial and temporal resolution crop water stress 
monitoring of corn within a greenhouse. - Computers and Electronics in Agriculture 121: 149-159. https://doi.org/10.1016/j.compag.2015.12.007.

[21] Monteith, J. L., Unsworth, M. H. (1990): Principles of Environmental Physics. - Edward Arnold, London.

[22] Monteith, J. L., Unsworth, M. H. (2013): Principles of Environmental Physics: Plants, Animals, and the Atmosphere (Fourth Ed.). - Elsevier Ltd, Oxford, UK. https://doi.org/10.1016/B978-0-12-386910-4.00019-6.

[23] O'Shaughnessy, S. A., Evett, S. R., Colaizzi P. D., Howell, T. A. (2010): Automatic irrigation scheduling of grain sorghum using a CWSI and time threshold. - Decennial Irrigation Association Conference Michigan. DOI: 10.13031/2013.35814.

[24] Omidi, A. H., Khazaei, H., Monneveux, P., Stoddard, F. (2012): Effect of cultivar and water regime on yield and yield components in safflower (Carthamus tinctorius L.). Turkish Journal of Field Crops 17: 10-15. http://www.fieldcrops.org/assets/pdf/product512cbe038c930.

[25] Orta, A. H., Erdem, Y., Erdem, T. (2003): Crop water stress index for watermelon. Scientia Horticulture 98: 121-130. https://doi.org/10.1016/S0304-4238 (02)00215-7.

[26] Rezaei, E. E., Webber, H., Gaiser, T., Naab, J., Ewert, F. (2015): Heat stress in cereals: Mechanisms and modelling. - European Journal of Agronomy 64: 98-113. https://doi.org/10.1016/j.eja.2014.10.003.

[27] Siebert, S., Ewert, F., Rezaei, E. E., Kage, H., Graß, R. (2014): Impact of heat stress on crop yield - on the importance of considering canopy temperature. - Environmental Research Letters 90: 440-12. http://iopscience.iop.org/article/10.1088/17489326/9/4/044012/meta.

[28] Wall, G., Garcia, R., Kimball, B., Hunsaker, D., Pinter, P., Long, S., Osborne, C., Hendrix, D., Wechsung, F., Wechsung, G. (2006): Interactive effects of elevated carbon dioxide and drought on wheat. - Agronomy Journal 98: 354-381. DOI: 10.2134/agronj2004.0089.

[29] Yazar, A., Howell, T. A., Dusek, D. A., Copeland, K. S. (1999): Evaluation of crop water stress index for LEPA irrigated corn. - Irrigation Science 18: 171-180. https://link.springer.com/article/10.1007/s002710050059.

[30] Zia, S., Romano, G., Spreer, W., Sanchez, C., Cairns, J., Araus, J. L., Müller, J. (2012): Infrared thermal imaging as a rapid tool for identifying water stress tolerant maize genotypes of different phenology. - Journal of Agronomy and Crop Science 199(2): 7584. https://doi.org/10.1111/j.1439-037X.2012.00537.x. 